\title{
APLIKASI PERMAINAN SEBAGAI MEDIA PEMBELAJARAN PETA DAN BUDAYA SUMATERA UNTUK SISWA SEKOLAH DASAR \\ ${ }^{1}$ Dyah Ayu Megawaty, ${ }^{2}$ Damayanti, ${ }^{3}$ Zakaria Sani Assubhi, ${ }^{4}$ Maulana Aziz Assuja \\ 1,2,3,4 Universitas Teknokrat Indonesia, Lampung \\ e-mail : ${ }^{1}$ dyahayumegawaty@teknokrat.ac.id
}

\begin{abstract}
Indonesia secara umum mempunyai banyak keanekaragaman budaya dari berbagai pulau. Pulau Sumatera termasuk dalam pulau-pulau terbesar di Indonesia. Seiring dengan perkembangan zaman, kebudayaan yang ada di Indonesia pada saat ini secara perlahan mulai terlupakan. Oleh karena itu tujuan dari penelitian ini adalah memberikan alternatif lain untuk mengenalkan pulau Sumatera pada pelajar sekolah dasar melalui aplikasi permainan sehingga siswa tidak mudah bosan dan tertarik untuk mengetahui sejarah masing-masing provinsi, rumah adat dan pakaian adatnya. Penelitian ini dikembangkan dengan menggunakan construct 2 dan metode pengembangan Multimedia Development Life Cycle. Hasil penelitian ini berupa aplikasi permainan pengenalan peta dan budaya Sumatera yang dapat dijalankan melalui smartphone berbasis android dengan disertakan latihan soal, untuk mengetahui sejauh mana kemampuan siswa mendalami materi yang didapat dari game ini. Aplikasi ini telah diuji kepada siswa sekolah dasar dengan rata-rata hasil $94 \%$ atau sangat baik.
\end{abstract}

Keywords: Construct 2, Game Edukasi, MDLC, Peta dan Budaya Sumatera, Sekolah Dasar

\section{PENDAHULUAN}

Indonesia adalah negara yang memiliki berbagai ragam budaya dan adat istiadat yang melekat dengan ragam etnis, ras budaya serta agama yang majemuk. [1]. Indonesia secara umum mempunyai banyak keanekaragaman budaya dari berbagai pulau. Pulau Sumatera termasuk dalam pulau-pulau terbesar di Indonesia. Pulau Sumatera mempunyai luas $473.481 \mathrm{~km}^{2}$, terletak dibagian barat gugusan kepulauan Nusantara. Berdasarkan luasnya, Sumatera merupakan pulau terbesar keenam didunia. Pulau ini membujur dari barat laut ke arah tenggara dan melintasi khatulistiwa, seolah membagi pulau Sumatera atas dua bagian, Sumatera belahan bumi utara dan Sumatera belahan bumi selatan. Pulau Sumatera terletak dibagain barat gugusan kepulauan Indonesia. Secara geografis Pulau Sumatera berada di posisi $6^{\circ} \mathrm{LU}-6^{\circ} \mathrm{LS}$ dan antara $95^{\circ} \mathrm{BB}-109^{\circ} \mathrm{BT}$. Disebelah utara berbatasan dengan dengan Teluk Benggala, disebelah selatan berbatasan dengan Selat Malaka, disebelah selatan berbatasan dengan Selat Sunda dan disebelah barat berbatasan dengan Samudra Hindia. Sumatera dibagi menjadi 10 Provinsi dimulai dari paling barat pulau yaitu Aceh, Sumatera Utara, Riau, Kep. Riau, Sumatera Barat, Jambi, Bengkulu, Bangka Belitung, Sumatera Selatan, dan yang paling timur dari Pulau Sumatera yaitu Lampung [2]. Seiring dengan perkembangan zaman, kebudayaan yang ada di Indonesia pada saat ini secara perlahan mulai terlupakan, Hal ini terjadi karena begitu banyak kebudayaan asing yang masuk dan dengan mudah diterima oleh masyarakat, Terutama banyak diantaranya anak-anak dan kaum muda lebih menyukai budaya asing dari pada budaya tanah air [3]. Sehingga perlu adanya upaya untuk menarik kembali minat belajar kebudayaan Indonesia.

Perkembangan teknologi informasi dan komunikasi atau yang sering dikenal dengan istilah ICT (Information and Communication Technologies) di era sekarang berjalan sangat cepat di Indonesia. Percepatan perkembangan tersebut berdampak ke berbagai bidang. Pendidikan adalah salah satu bidang yang tidak terlepas dari dampak perkembangan ICT. Pembelajaran dengan memanfaatkan atau mengintegrasikan ICT dapat memudahkan guru maupun siswa karena memberikan kesempatan kepada siswa untuk belajar secara dinamis dan interaktif. [4]. Perkembangan teknologi turut berperan dalam perkembangan game sendiri 
sehingga game saat ini dapat dimainkan dari manapun dan kapanpun diinginkan [5]. Teknologi game berkembang dari waktu ke waktu sebagai salah satu alternatif media pembelajaran [6].

Game Edukasi adalah game digital yang dirancang untuk pengayaan pendidikan (mendukung Pengajaran dan pembelajaran [7]. Media ini memiliki kelebihan dalam penyampaian materi pembelajaran. Dalam penyampaian materi, game edukasi membuat pembelajaran tersebut menjadi sebuah permainan dimana peserta didik belajar ketika mereka berhadapan atau menemukan misi, tantangan, dan hambatan didalam game edukasi [8]. Pemanfaatan game saat ini masih digunakan atas dasar hiburan semata. Adanya tema game yang semakin berkembang masih belum cukup menampung game dengan tema edukasi. Apalagi perhatian terhadap keanekaragaman budaya Indonesia semakin berkurang [9]. Adanya game ini diharapkan dapat membantu anak-anak usia sekolah dasar agar lebih mengenal dan menambah pengetahuan mereka tentang keanekaragaman budaya Indonesia [10].

Saat ini media pembelajaran game sudah merahbah ke aplikasi berbasis android, diantaranya game untuk pembelajaran. Android merupakan salah satu teknologi yang bisa dimanfaatkan sebagai sistem operasi berbasis open source yang membebaskan pengguna untuk mengembangkan aplikasi [11]. Android merupakan platform yang paling populer bagi ponsel di dunia. Lebih dari 190 negara di seluruh dunia menggunakan Android. Banyak pengguna menggunakan Android untuk mencari aplikasi, permainan dan konten digital lainnya. Android menjadi sistem operasi mobile yang tumbuh paling cepat. Setiap hari lebih dari 1 juta perangkat Android diaktifkan di seluruh dunia [12]

Dari uraian diatas, maka perlu adanya game pengenalan budaya ini diharapkan dapat membantu anak anak usia dini lebih mengenal budaya Indonesia dan bisa juga menanam minat anak usia dini dalam kecintaanya dengan budaya Indonesia [13].

\section{METODOLOGI PENELITIAN}

Multimedia adalah penggunaan beberapa media untuk menyajikan informasi.Kombinasi ini dapat berisi teks, grafik, animasi, gambar, video, dan suara [14]. Metodelogi yang digunakan dalam mengembangkan aplikasi permainan ini adalah Multimedia Development Life Cycle (MDLC) [15]. Metode pengambangan multimedia terdiri dari 6 tahapan yaitu, Concept, Design, Material Collecting, Assembly, testing, dan Distribution.

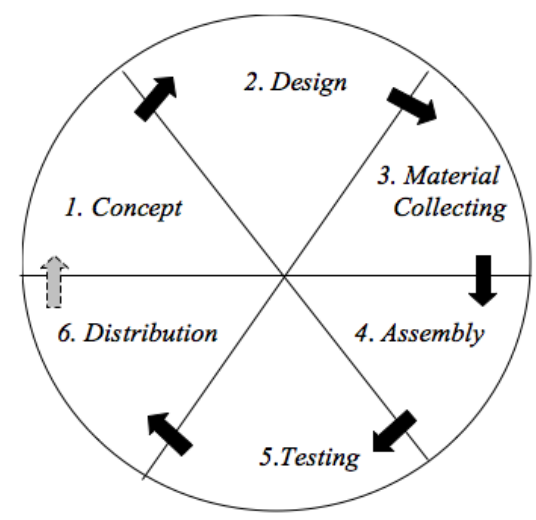

Gambar 1. Multimedia Development Life Cycle (MDLC).

\section{Concept}

Tahap konsep (consept) adalah tahap untuk menentukan tujuan dan siapa pengguna program (identifikasi audience). Selain itu menentukan macam aplikasi (presentasi, interaktif, dll) dan tujuan aplikasi (hiburan, pelatihan, pembelajaran, dll). 


\section{Design}

Perancangan (design) adalah tahap membuat spesifikasi mengenai arsitektur program, gaya, tampilan dan kebutuhan material/bahan untuk program.

\section{Material Collecting}

Tahap dimana pengumpulan bahan yang sesuai dengan kebutuhan dilakukan. Tahap ini dapat dikerjakan paralel dengan tahap assembly. Pada beberap kasus, tahap Material Collecting dan tahap Assembly akan dikerjakan secara linear tidak paralel.

4. Assembly

Tahap assembly (pembuatan) adalah tahap dimana semua objek atau bahan media dibuat.

5. Testing

Pada tahap ini, aplikasi akan disimpan dalam suatu media penyimpanan. Jika media penyimpanan tidak cukup untuk menampung aplikasinya, kompresi terhadap aplikasi tersebut akan dilakukan. Tahap ini juga dapat disebut tahap evaluasi untuk pengembangan produk yang sudah jadi supaya menjadi lebih baik. Hasil evaluasi ini dapat digunakan sebagai masukan untuk tahap concept pada produk selanjutnya.

6. Distribution

Tahapan dimana aplikasi disimpan dalam suatu media penyimpanan. Pada tahap ini jika media penyimpanan tidak cukup untuk menampung aplikasinya, maka dilakukan kompresi terhadap aplikasi tersebut.

\subsection{Objek Penelitian}

Penelitian ini dilakukan pada SDN 2 Panjang Utara Bandar Lampung. Aktifitas yang dilakukan adalah menyebarkan kuisioner kepada siswa/i mengenai pembelajaran Peta dan Budaya Sumatera dan pengambilan data-data pendukung sebagai bahan analisis seputar pembelajaran kebudayaan Sumatera.

\subsection{Tahap Penelitian}

Berdasarkan siklus tahapan penelitian multimedia, maka tujuan dan literature dari tahapan multimedia ini dirancang dengan sebuah work Breakdown Structure (WBS) agar dapat dijelaskan secara rinci dan bertahap yang dapat dilihat pada gambar berikut:

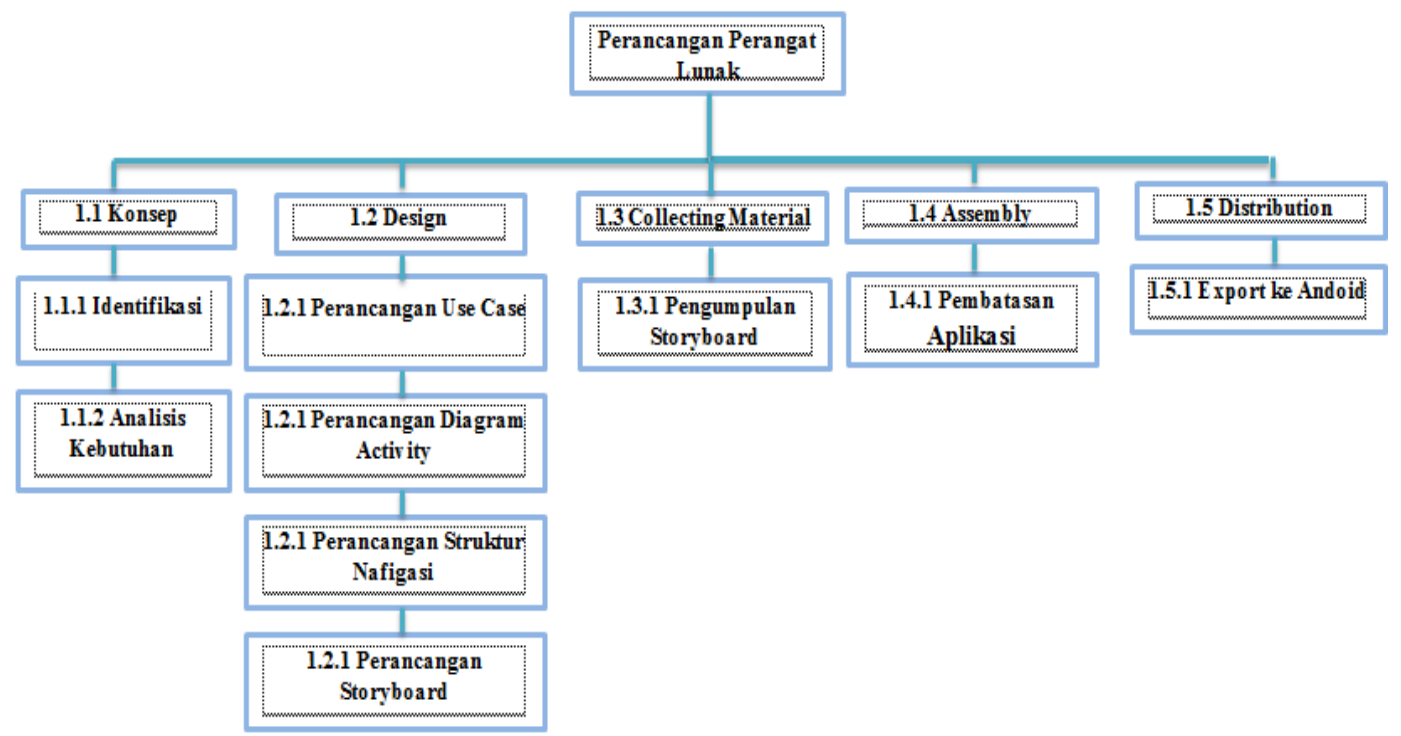

Gambar 2. Tahapan Penelitian 
(C2021 Ilmu Komputer Unila Publishing Network all rights reserved

\section{Jurnal Komputasi}

\section{HASIL DAN PEMBAHASAN}

Pada penelitian ini spesifikasi yang akan dibuat berdasarkan metodologi dan tahapan penelitian adalah sebagai berikut:

1. Perancangan Usecase

Use case diagram menggambarkan fungsionalitas yang diharapkan dari sebuah sistem.

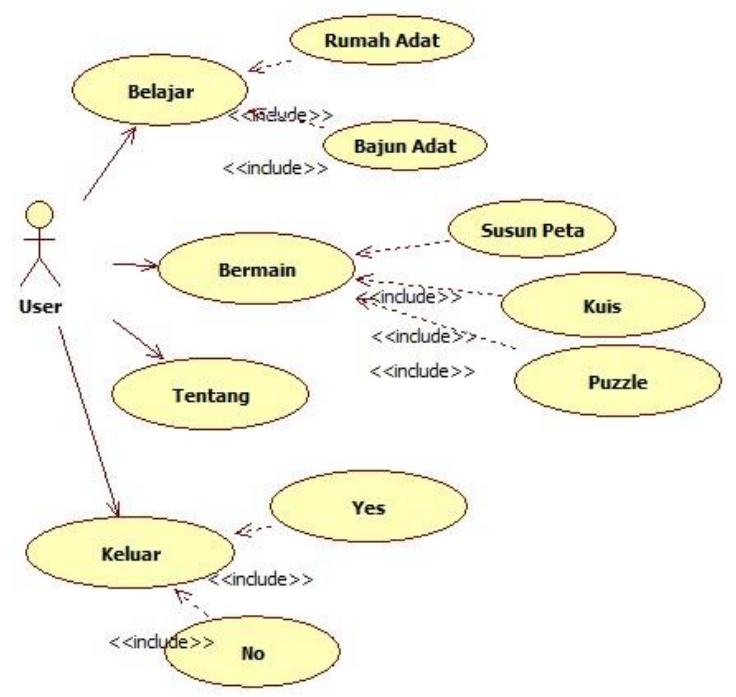

Gambar 3. Usecase Diagram Game Peta dan Budaya Sumatera

2. Tampilan Aplikasi

Sesuai dengan rancangan yang sudah dibuat, maka berikut adalah tampilan Game Peta dan Budaya Sumatera

a) Halaman loading screen

Tampilan pertama kali ketika game dijalankan, halaman loading screen berisikan logo :

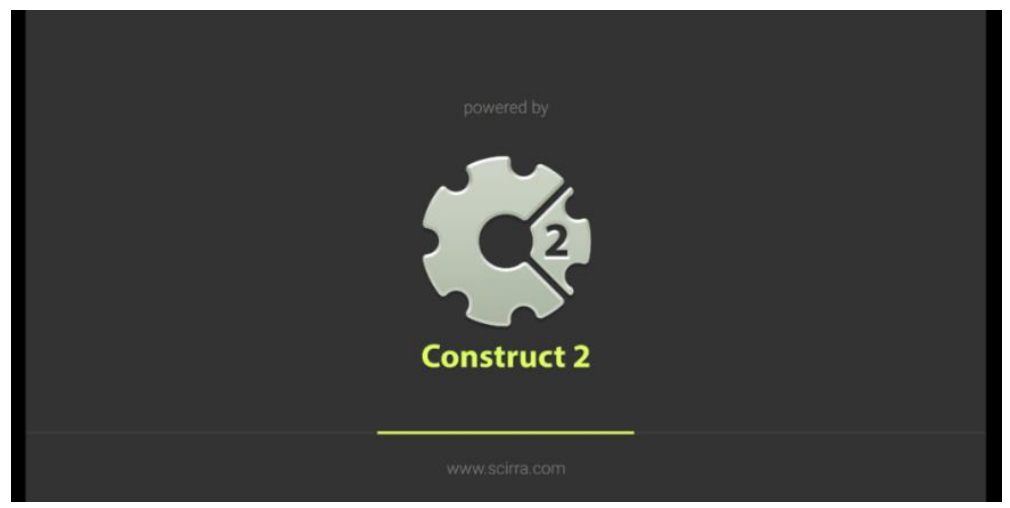

Gambar 4. Tampilan Loading Screen

b) Tampilan Menu Utama Game

Pada tampilan menu utama game ada berberapa tombol, mulai dari tombol belajar, bermain, tentang game dan tombol keluar game. 


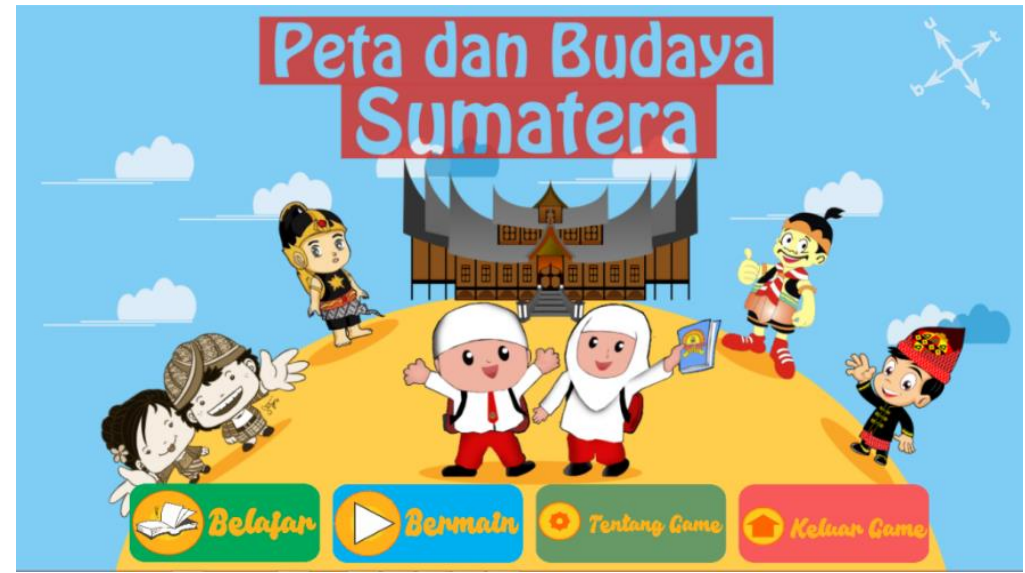

Gambar 5. Tampilan Menu Utama

c) Menu Pilih Belajar

Halaman menu belajar berisikan pilihan game dari belajar baju adat dan rumah adat.

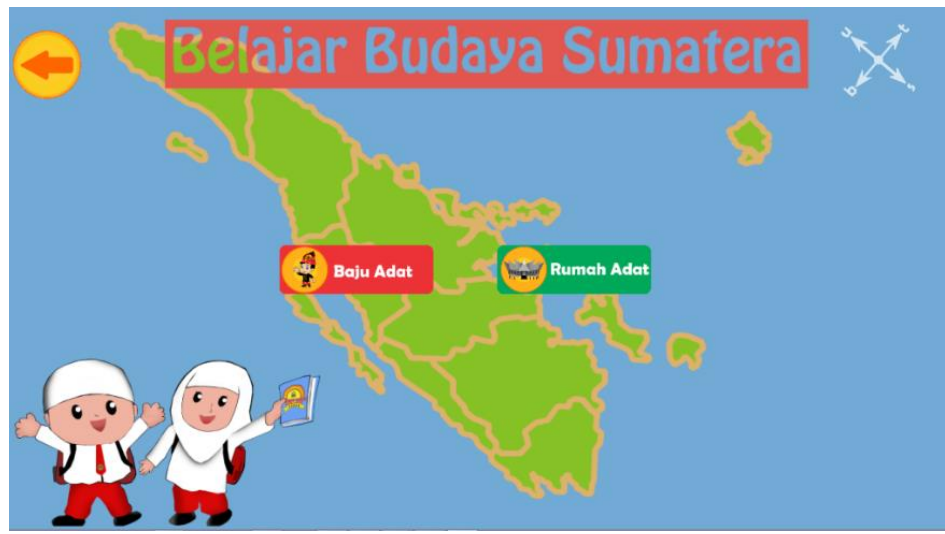

Gambar 6. Tampilan Menu Belajar

d) Menu Bermain Susun Peta Sumatera

Menu ini menampilkan susun peta Sumatera.

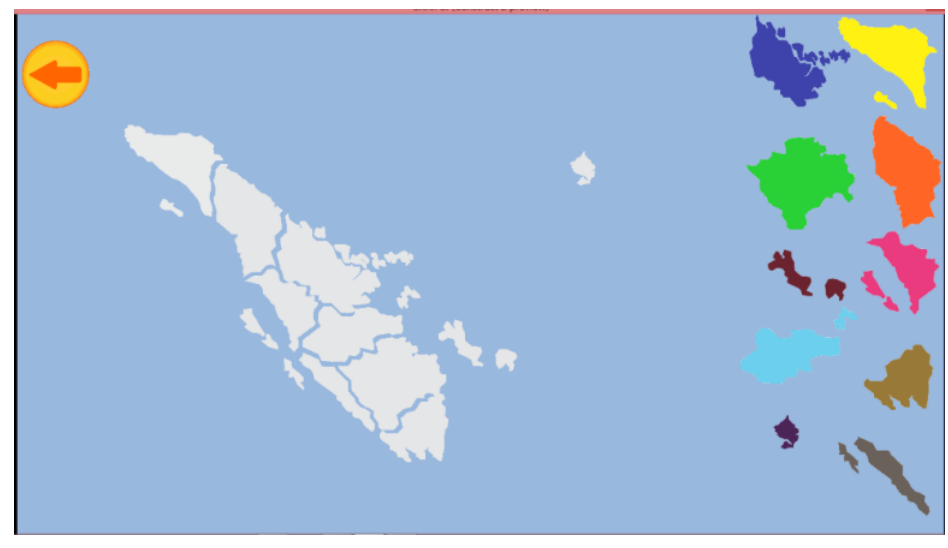

Gambar 7. Menu Bermain Susun Peta 


\section{Jurnal Komputasi}

e) Menu Bermain Kuis

Menu ini menampilkan kuis yang mana pengguna ditantang untuk menjawab pertanyaan yang telah disediakan. Pengguna diharuskan menjawab pertanyaan dengan benar dalam waktu 30 detik. Setiap pertanyaan yang berhasil dijawab dengan benar, maka akan mendapat nilai 10 .

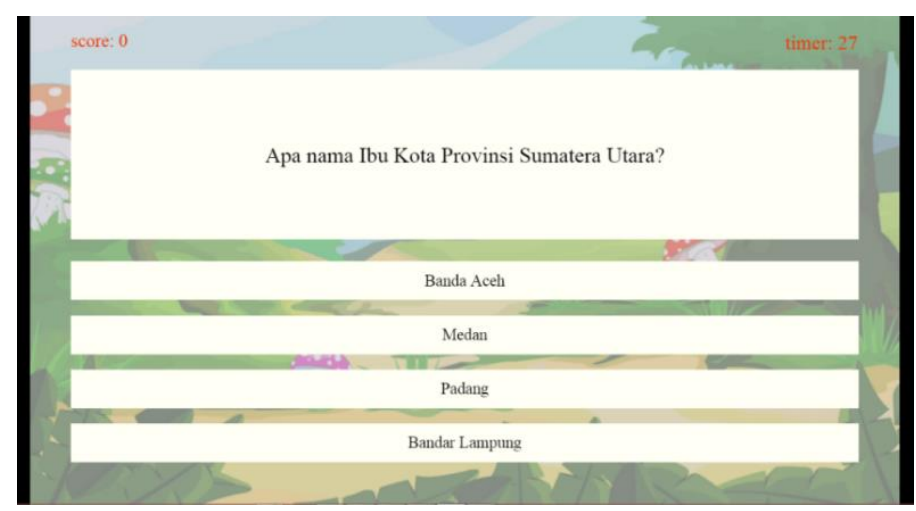

Gambar 8. Menu Bermain Kuis

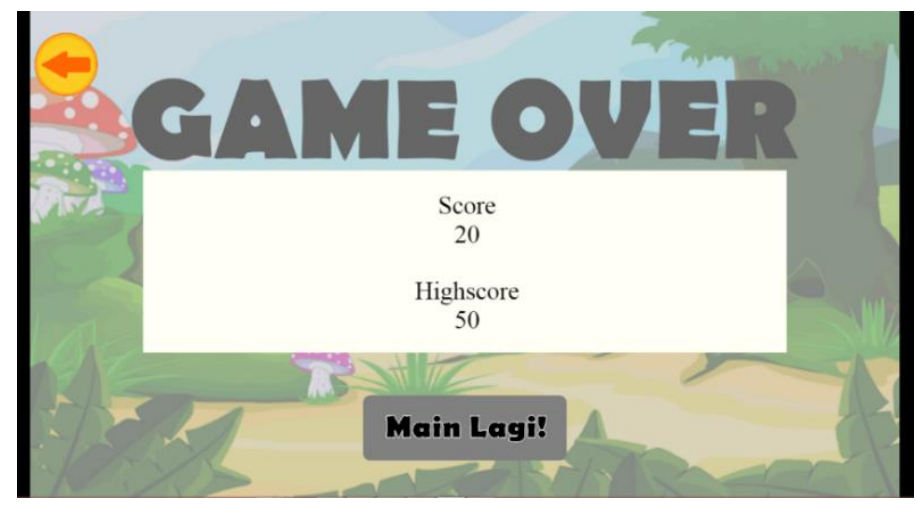

Gambar 9. Tampilan Skor Kuis

f) Menu Bermain Puzzel

Pada menu ini, pengguna diharuskan menyusun beberapa gambar yang tepisah menjadi satu gambar utuh.

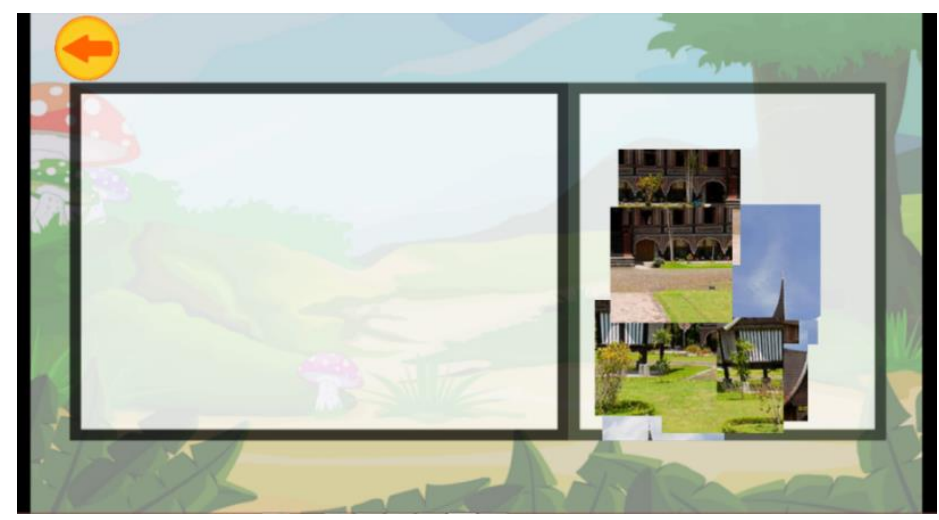

Gambar 10. Menu Bermain Puzzle

Pengujian dilakukan secara objektif, pengujian ini dilakukan secara langsung terhadap siswa/i. Proses yang dilakukan dengan menggunakan kusioner terhadap user atau pengguna dari aplikasi yang dibuat, selanjutnya dibagikan kepada pengguna dengan mengambil sebagian sampel pegguna 10 orang siswa/i. kusioner ini terdiri 
(C2021 Ilmu Komputer Unila Publishing Network all rights reserved

\section{Jurnal Komputasi}

dari 11 pertanyaan yang diberikan dengan skala SS (Sangat Setuju) $=5, \mathrm{~S}$ (Setuju) $=4, \mathrm{~N}(\mathrm{Netral})=3$, TS $($ Tidak Setuju $)=2$, STS $($ Sangat Tidak Setuju $)=1$. Hasil pengujian dapat dilihat pada Tabel berikut:

Tabel 1. Hasil Nilai Responden

\begin{tabular}{|c|c|c|c|c|c|}
\hline \multirow{2}{*}{ Responden } & \multicolumn{5}{|c|}{ Hasil } \\
\cline { 2 - 6 } & SS & S & N & TS & STS \\
\hline $\mathbf{1}$ & 10 & 1 & 0 & 0 & 0 \\
\hline $\mathbf{2}$ & 6 & 5 & 0 & 0 & 0 \\
\hline $\mathbf{3}$ & 10 & 1 & 0 & 0 & 0 \\
\hline $\mathbf{4}$ & 11 & 0 & 0 & 0 & 0 \\
\hline $\mathbf{5}$ & 5 & 6 & 0 & 0 & 0 \\
\hline $\mathbf{6}$ & 4 & 7 & 0 & 0 & 0 \\
\hline $\mathbf{7}$ & 10 & 1 & 0 & 0 & 0 \\
\hline $\mathbf{8}$ & 9 & 1 & 1 & 0 & 0 \\
\hline $\mathbf{9}$ & 9 & 2 & 0 & 0 & 0 \\
\hline $\mathbf{1 0}$ & 7 & 4 & 0 & 0 & 0 \\
\hline Total & $\mathbf{8 1}$ & $\mathbf{2 4}$ & $\mathbf{1}$ & $\mathbf{0}$ & $\mathbf{0}$ \\
\hline
\end{tabular}

Selanjutnya dilakukan perhitungan presentase pengujian sebagai berikut:

$\mathrm{SS}=81 \times 5=405, \mathrm{~S}=28 \times 4=112, \mathrm{~N}=1 \times 3=1, \mathrm{TS}=0, \mathrm{STS}=0$;

Skor hasil pengujian $=520$

Skor tertinggi $=19($ jumlah pertanyaan $) \times 5 \times 10($ responden $)=550$

$$
\begin{aligned}
\text { Presentase } & =\frac{\text { Skor hasil pengujian }}{\text { Skor tertinggi }} \times 100 \% \\
& =\frac{520}{550} \times 100 \% \\
& =94 \%
\end{aligned}
$$

Sehingga dapat disimpulkan dalam aspek pengujian game edukasi pengenalan peta dan budaya sumatera menggunakan cunstruc2 untuk anak SD memperoleh nilai 94\%

\section{KESIMPULAN}

Kesimpulan dari penelitian mengenai Media Pembelajaran Peta dan Budaya Sumatera adalah sebagai berikut

1. Media pembelajaran peta dan budaya sumatera ini dapat membantu para guru untuk menarik minat belajar siswa

2. Berdasakan hasil pengujian yang telah dilakukan aplikasi yang dibangun dapat diterima sesuai dengan kebutuhan pengguna baik dari segi isi, materi, visualisasi dan kenyamanan menggunakan aplikasi dengan presetase $94 \%$.

\section{UCAPAN TERIMA KASIH}

Penulis mengucapkan terima kasih kepada Universitas Teknokrat Indonesia yang telah memberi dukungan pendanaan/financial terhadap penelitian ini melalui skema Penelitian Pembinaan Kapasitas (PPK) tahun pelaksanaan 2020 dengan nomor kontrak 003/UTI/LPPM/E.1.1.VII/2020 


\section{DAFTAR PUSTAKA}

[1] M. Amin, "Pendidikan Multikultural," PILAR, vol. 9.1, pp. 24-34, 2018.

[2] Tim, Buku Sumatera, Jakarta: Badan Pengembangan Infrastruktur Wilayah (BPIW), 2017.

[3] B. Pane, X. Najoan and S. Paturisi, "Rancang Bangun Aplikasi Game Edukasi Ragam Budaya Indonesia," Jurnal Teknik Informatika, vol. 12.1, 2017.

[4] O. Irmade, "ANALISIS TINGKAT PENGGUNAAN ICT GURU TK KECAMATAN GROGOL KABUPATEN SUKOHARJO," JURNAL AUDI: Jurnal Ilmiah Kajian Ilmu Anak dan Media Informasi PAUD, vol. 3.2, pp. 101-107, 2018.

[5] T. Lijoed, D. Paseru and T. C. Suwanto, "GAME PENGENALAN RAGAM BUDAYA DAN ALAM SULAWESI UTARA," Jurnal Ilmiah Realtech, vol. 14.1, pp. 54-63, 2018.

[6] D. W. Putra, A. P. Nugroho and E. W. Puspitarini, "Game Edukasi Berbasis Android Sebagai Media Pembelajaran Untuk Anak Usia Dini," Jurnal Informatika Merdeka Pasuruan., vol. 1.1, pp. 46-58, 2016.

[7] Q. J. Adrian and A. Apriyanti, "Game Edukasi Pembelajaran Matematika untuk Anak SD Kelas 1 dan 2 Berbasis Android," Teknoinfo, vol. 13 (1), pp. 51-54, 2019.

[8] W. C. Setiawan, Sulthoni and S. Ulfa, "Pengembangan Multimedia Game Edukasi Ipa Lapisan Bumi Untuk MTS," Jurnal Kajian Teknologi Pendidikan, vol. 2.1, pp. 30-36, 2019.

[9] R. Parlika, D. N. Anggreini, M. Syafriansyah, R. Alhakim and Y. Faradhilla, "Educational Game for Introducing Indonesian Culture on Android Platform," INFORM, vol. 3.2, pp. 100-104, 2018.

[10] P. L. Ekawati and A. Z. Falani, "Pemanfaatan Teknologi Game Untuk Pembelajaran Mengenal Ragam Budaya Indonesia Berbasis Android," Jurnal Link, vol. 22 (2), pp. 30-36, 2015.

[11] A. Mulyanto, A. Apriyadi and P. Prasetyawan, "RANCANG BANGUN GAME EDUKASI "MATCHING AKSARA LAMPUNG" BERBASIS SMARTPHONE ANDROID.," Computer Engineering, Science and System Journal, vol. 3 (1), pp. 36-44, 2018.

[12] U. Ependi and N. Sopiah, "Aplikasi Media Belajar Matematika Berbasis Android," in Seminar Nasional Teknologi Informasi, 2015.

[13] A. J. Kurniawan and C. hermawan, "RANCANG BANGUN APLIKASI GAME EDUKASI PENGENALAN BUDAYA INDONESIA BERBASIS ANDROID," Jurnal Penelitian Dosen FIKOM (UNDA), vol. 10.2, 2019.

[14] R. Ariani and Festiyed, "Analisis Landasan Ilmu Pengetahuan dan Teknologi Pendidikan dalam Pengembangan Multimedia Interaktif," Jurnal Penelitian Pembelajaran Fisika, vol. 5.2, pp. 155-162, 2019.

[15] D. Nurdiana and A. Suryandi, "Perancangan Game Budayaku Indonesiaku Menggunakan Metode MDLC," Jurnal Petik, pp. 39-44, 2017. 
(C2021 Ilmu Komputer Unila Publishing Network all rights reserved 